\title{
WYKRYWANIE USZKODZEŃ WĘZŁÓW W MODELU RAMY STALOWEJ NA PODSTAWIE ANALIZY INERTANCJI
}

\begin{abstract}
W artykule przedstawiono możliwość detekcji uszkodzeń węzłów na podstawie analizy proporcji pomiędzy wytypowanymi fragmentami funkcji przejścia (FRF). W ramach zadania wykonano eksperyment na modelu laboratoryjnym dwukondygnacyjnej ramy portalowej, którą poddano testom dynamicznym i dla której określono model modalny. Funkcję przejścia odpowiadającą wybranym punktom układu potraktowano jako sygnał w dziedzinie częstotliwości. Wyznaczono odcięte środków ciężkości kwadratów sygnału wybranych fragmentów funkcji, które następnie potraktowano jako dane wejściowe w metodzie wektorów nośnych. Zaproponowane podejście umożliwia skuteczną detekcję uszkodzeń węzłów badanego modelu.
\end{abstract}

Słowa kluczowe: detekcja uszkodzeń, SHM, FRF, Support Vector Machines (SVM)

\section{Wprowadzenie}

Wykrywaniu uszkodzeń w konstrukcjach budowlanych poświęcono już wiele uwagi. Podstawową metodą oceny stanu konstrukcji jest inspekcja wizualna, kosztowna, czasochłonna, wymagająca doświadczonego eksperta i często niemożliwa do przeprowadzenia bez wyłączenia obiektu z użytkowania. Ze względu na wymienione niedogodności coraz większą popularnością cieszą się metody nieniszczące, bazujące na ocenie stanu konstrukcji na podstawie danych pozyskanych w wyniku pomiarów nowoczesnymi metodami. Główną zaletą metod nieniszczących jest możliwość ciągłego monitorowania stanu konstrukcji bez ingerencji w jej strukturę, w trakcie normalnej eksploatacji obiektu. Jedną $\mathrm{z}$ takich metod jest np. pomiar przyspieszeń wybranych punktów wzbudzonej dynamicznie konstrukcji z jednoczesną rejestracją siły wymuszającej. Na pod-

\footnotetext{
${ }^{1}$ Autor do korespondencji / corresponding author: Dominika Ziaja, Politechnika Rzeszowska, Zakład Mechaniki Konstrukcji, ul. Poznańska 2, 35-959 Rzeszów; tel. 178651618; dziaja@prz.edu.pl

${ }^{2}$ Bartosz Miller, Politechnika Rzeszowska, Zakład Mechaniki Konstrukcji, ul. Poznańska 2, 35-959 Rzeszów; tel. 178651623; bartosz.miller@prz.edu.pl
} 
stawie zgromadzonych danych wykonywana jest analiza modalna, która umożliwia określenie postaci drgań swobodnych układu, odpowiadających im częstotliwości, a także współczynników tłumienia. Brownjohn i inni w pracy [1] przedstawili przykłady konstrukcji, w których zaimplementowano systemy bazujące na pomiarze drgań, opisując zalety i wady wykorzystanej metody.

Wyniki prezentowanych w tym artykule badań opierają się na informacjach otrzymanych $\mathrm{z}$ analizy modalnej. Jednak zastosowane podejście wykorzystuje nie popularnie stosowaną analizę zmian wartości częstotliwości i współczynników tłumienia dla poszczególnych form drgań swobodnych, a informacje o zmianie funkcji przejścia (Frequency Response Function, FRF). Funkcja przejścia opisuje relację pomiędzy wymuszeniem a rejestrowaną odpowiedzią konstrukcji [2]. Możliwość wykorzystania funkcji przejścia do detekcji uszkodzeń została zaprezentowana między innymi w [3], [4], [5] i [6]. W [3] funkcję przejścia potraktowano jako sygnał. Różnica pomiędzy energią takiego sygnału dla stanu z uszkodzeniem i bez umożliwiła skuteczne wykrywanie uszkodzenia. Przeprowadzony eksperyment bazował niestety wyłącznie na danych numerycznych. Nieco inne podejście zaproponowano w pracy [4], gdzie wykazano, że wystąpienie uszkodzenia w układzie powoduje przesunięcie wykresu funkcji w stronę niższych częstotliwości, a ocena, czy uszkodzenie wystąpiło czy nie możliwa jest poprzez wizualne porównanie funkcji dla układu wzorcowego i uszkodzonego. W pracy [5] pokazano skuteczność detekcji uszkodzeń na rzeczywistym obiekcie (most), a w [6] wykorzystano FRF do identyfikacji uszkodzenia w postaci zmiany sztywności połączeń.

Wnioski prezentowane w niniejszym artykule bazują wyłącznie na danych otrzymanych z eksperymentu na modelu fizycznym. Dane eksperymentalne wymagają wnikliwej analizy, do której można wykorzystać różnego rodzaju metody jak choćby te, zaprezentowane w pracach [5], [7], [8] i [9]. W dalszej części artykułu zostanie pokazane, że analiza zmian kształtu funkcji przejścia z wykorzystaniem metody wektorów nośnych (ang: Support Vector Machines, SVM, [10]) umożliwia skuteczną detekcję uszkodzeń węzłów badanej ramy.

\section{Opis procedury badawczej}

\subsection{Model laboratoryjny}

W badaniach wykorzystano model stalowej, dwukondygnacyjnej ramy portalowej pokazany na Rys. 1, wykonanej z IPE 80, ze stali S355. Wymiary w osiach elementów przedstawiono na Rys. 2. Wszystkie połączenia rygiel-słup, pokazane na Rys. 3, wykonano jako doczołowe z czterema rzędami śrub M8 klasy 8.8. Połączenie z fundamentem przedstawiono na Rys 4. 


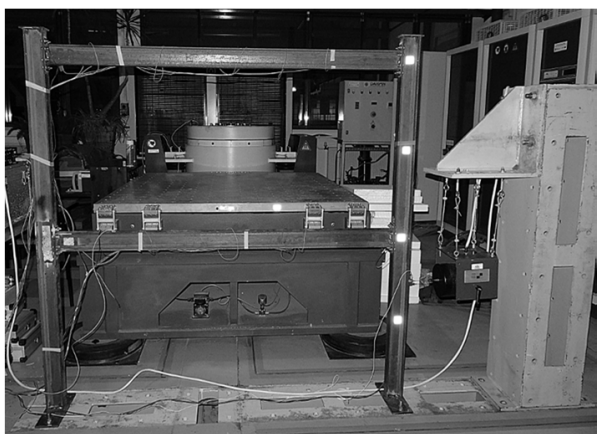

Rys. 1. Model laboratoryjny

Fig. 1. Laboratory model of the frame

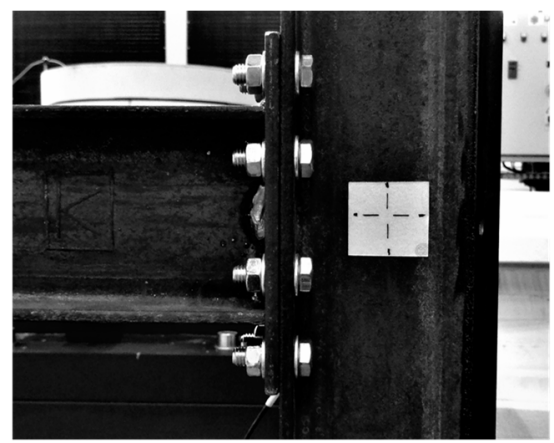

Rys. 3. Połączenie rygiel - słup

Fig. 3. Beam-to-column connection

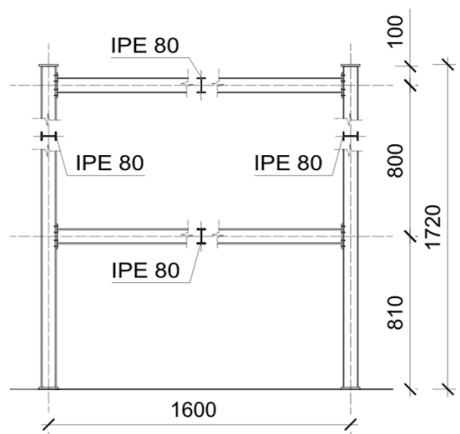

Rys. 2. Schemat modelu laboratoryjnego, wymiary w mm

Fig. 2. Scheme of the model, dimensions in $\mathrm{mm}$

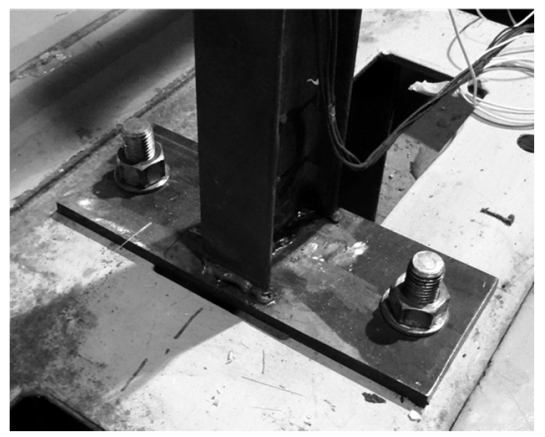

Rys. 4. Połączenie z fundamentem

Fig. 4. Column footing

\subsection{Przeprowadzone pomiary}

Model laboratoryjny poddano badaniom dynamicznym. Ponieważ prezentowane badania są częścią szerszego tematu, mającego na celu opracowanie skutecznych procedur wykrywania uszkodzeń w konstrukcjach budowlanych przy wykorzystaniu różnych, nieniszczących metod pomiarowych, w trakcie pomiarów wykorzystano czujniki przyspieszeń rozmieszczone na ramie w konfiguracji pokazanej na Rys. 5. Oznaczenia przyjęte na tym rysunku: 1D - czujnik jednoosiowy, 2D - czujnik trójosiowy mierzący przyspieszenia tylko w 2 wybranych kierunkach, 3D - czujnik trójosiowy; $\mathrm{x}, \mathrm{y}, \mathrm{z}$ - kierunki mierzonych przyspieszeń. $\mathrm{W}$ ramie wzbudzano drgania używając wzbudnika modalnego. Drgania wzbudzano białym szumem, w taki sposób, że po transformacji do dziedziny częstotliwości rejestrowany sygnał miał zakres $0-200 \mathrm{~Hz}$ i rozdzielczość $0.097 \mathrm{~Hz}$. Do wykonania pomiarów użyto wielokanałowego rejestratora/analizatora LMS Scadas Mobile wraz z oprogramowaniem Siemens LMS Test.Lab 15 (z modułem MIMO FRF Testing). 
W trakcie eksperymentu wykonywano pomiary na ramie bez uszkodzenia (wszystkie śruby $\mathrm{w}$ każdym $\mathrm{z}$ połączeń rygiel-słup dokręcone $\mathrm{z}$ takim samym momentem) oraz z wprowadzonym uszkodzeniem (rozkręcone dwa zewnętrzne rzędy śrub w jednym z połączeń). W ten sposób zgromadzono 30 wzorców bez uszkodzenia i 12 z uszkodzeniem (po 3 dla każdego węzła).

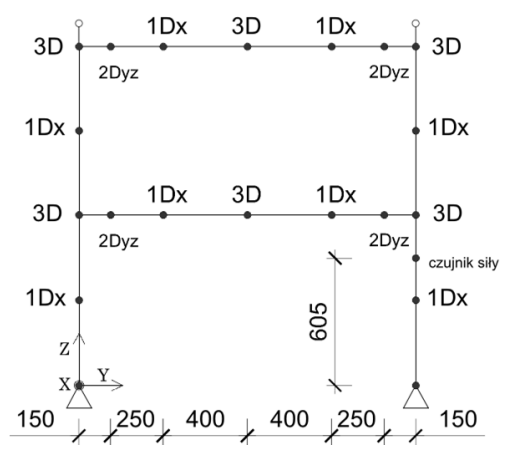

Rys. 5. Rozmieszczenie czujników, wymiary w $\mathrm{mm}$

Fig. 5. Location of accelerometers, dimensions in $\mathrm{mm}$
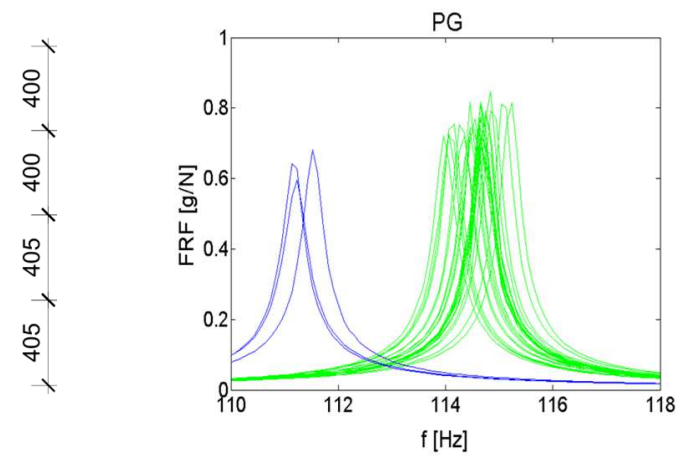

Rys. 6. Fragment funkcji przejścia w przedziale 110-118 Hz dla prawego, górnego węzła. Kolor niebieski - wzorce uszkodzone, zielony - bez uszkodzenia

Fig. 6. Fragment of FRF function in the range of 110$118 \mathrm{~Hz}$ for the right upper node, for damaged (blue) and undamaged (green) patterns

\section{Analiza danych pomiarowych}

Szczegółowej analizie poddano funkcje przejścia otrzymane z czujników zlokalizowanych po obu stronach każdego z węzłów, czujniki te rejestrowały przyspieszenia w kierunku Y (poziomo w płaszczyźnie ramy) oraz Z (pionowo, w płaszczyźnie ramy). Badano relacje pomiędzy kształtem funkcji przejścia po wewnętrznej i zewnętrznej stronie węzłów (np. różnice pomiędzy wartościami funkcji, proporcje pomiędzy nimi), a także możliwość detekcji uszkodzenia na podstawie informacji otrzymanych tylko z jednej strony węzła. W wyniku przeprowadzonych rozważań uznano, że najlepsze możliwości detekcji dają funkcje przejścia na kierunku Y (poziomo w płaszczyźnie ramy), Odpowiadające czujnikom umieszczonym na słupach, na przecięciu teoretycznych osi rygli i słupów. W dalszej części artykułu ograniczono się wyłącznie do przedstawienia wyników bazujących na tych funkcjach. Dodatkowa korzyść płynąca z takiego podejścia to fakt, że do wykrycia uszkodzenia węzła wystarczy jeden czujnik przyłożony do dowolnego połączenia rygiel - słup. Na Rys. 6 przedstawiono fragment wykresu wartości bezwzględnej z funkcji przejścia dla prawego górnego węzła (w zakresie częstotliwości 110-118 Hz), a na Rys. 7 zamieszczono wykresy dla każdego z 4 węzłów, rozróżniając sytuację z uszkodzeniem (kolor niebieski) 

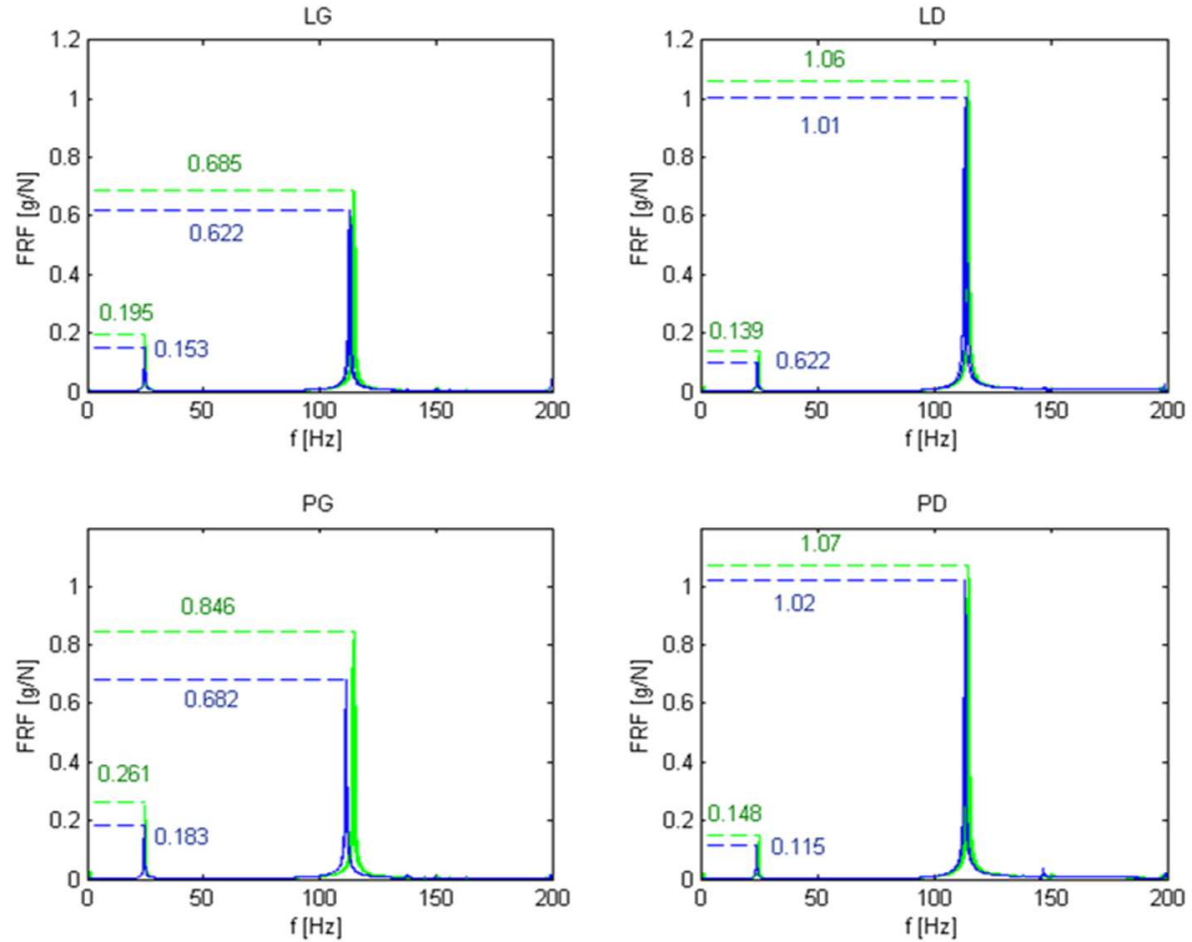

Rys. 7. Porównanie wartości bezwzględnej z funkcji przejścia dla stanu bez uszkodzenia (kolor zielony) i z uszkodzeniem (kolor niebieski) dla każdego z analizowanych czujników (L - lewy, P- prawy, G- górny, D - dolny węzeł)

Fig. 7. Comparison of the absolute value of the FRF function for failure-free state (green) and fault (blue) for each of the analyzed sensors (L - left, P- right, G- top, D - bottom node)

i bez uszkodzenia (kolor zielony), przy czym w sytuacji towarzyszącej uszkodzeniu użyto wyłącznie informacji o FRF przy znanym, uszkodzonym węźle (informacja z pozostałych czujników na tym rysunku została pominięta).

Porównując zamieszczone wykresy można zauważyć, że pojawieniu się uszkodzenia towarzyszy przesunięcie ekstremów na wykresie funkcji w stronę niższych częstotliwości, co potwierdza zmniejszenie sztywności układu. Dodatkowo widoczne są także zmiany w wartości amplitudy - dla wzorców uszkodzonych amplitudy są niższe.

Aby liczbowo opisać zmiany zachodzące na skutek uszkodzenia funkcję przejścia potraktowano jak sygnał i wyznaczono początkowo odciętą środka ciężkości kwadratu sygnału w pełnym zakresie, zgodnie ze wzorem [11]:

$$
\bar{n}_{x^{2}}{ }^{1}=\sum_{i=-\infty}^{\infty} n \cdot x^{2}(n) / \sum_{i=-\infty}^{\infty} x^{2}(n)
$$

gdzie: $\mathrm{x}$ - oznacza wartość sygnału dyskretnego,

$$
\mathrm{n} \text { - oznacza numer kroku. }
$$


Następnie dla każdego wzorca wyznaczono wartości odciętych środka ciężkości kwadratu sygnału w przedziałach $23-27$ Hz i 110-118 Hz. Na Rys. 8 zamieszczono obliczone odcięte wyznaczone dla pełnego zakresu częstotliwości, natomiast na Rys. 9 przedstawiono każdy wzorzec jako punkt, dla którego na osi poziomej odłożono położenie odciętej dla pierwszego przedziału, na osi pionowej zaś wartość odciętej dla przedziału drugiego.

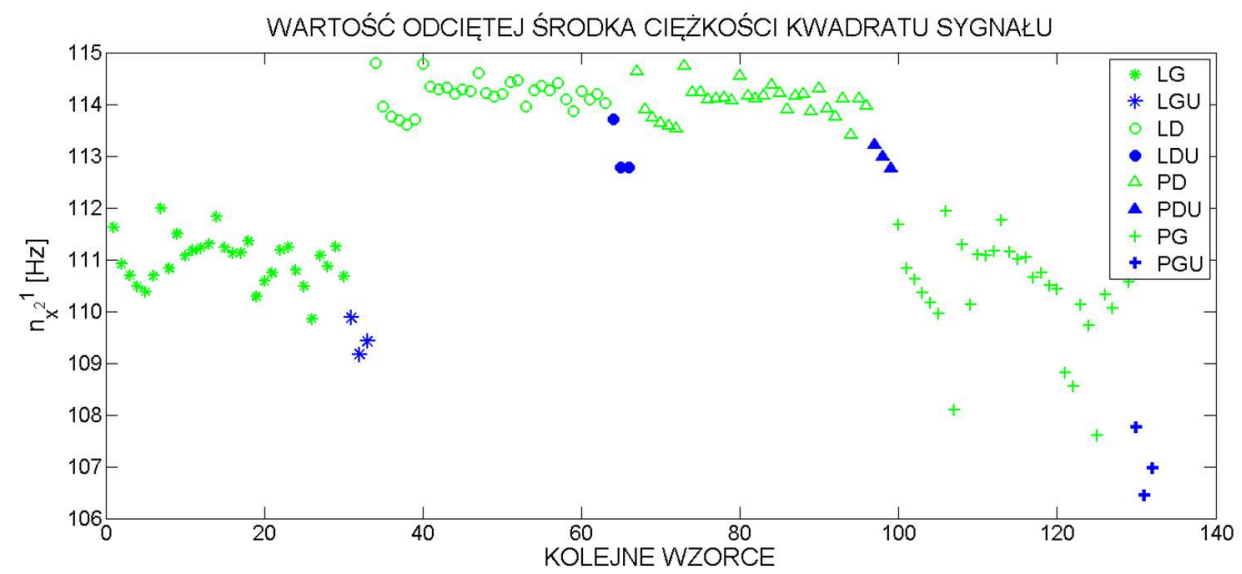

Rys. 8. Porównanie wartości odciętej środka ciężkości kwadratu sygnału dla wszystkich węzłów (oznaczenia: L - lewy, P- prawy, G- górny, D - dolny węzeł, U - wzorzec uszkodzony, kolor zielony - wzorce bez uszkodzenia)

Fig. 8. Comparison of the center of gravity of the squared signal for all nodes (L - left, P - right, $\mathrm{G}$ - top, $\mathrm{D}$ - bottom node, $\mathrm{U}$ - damaged pattern, green color - patterns without damage)

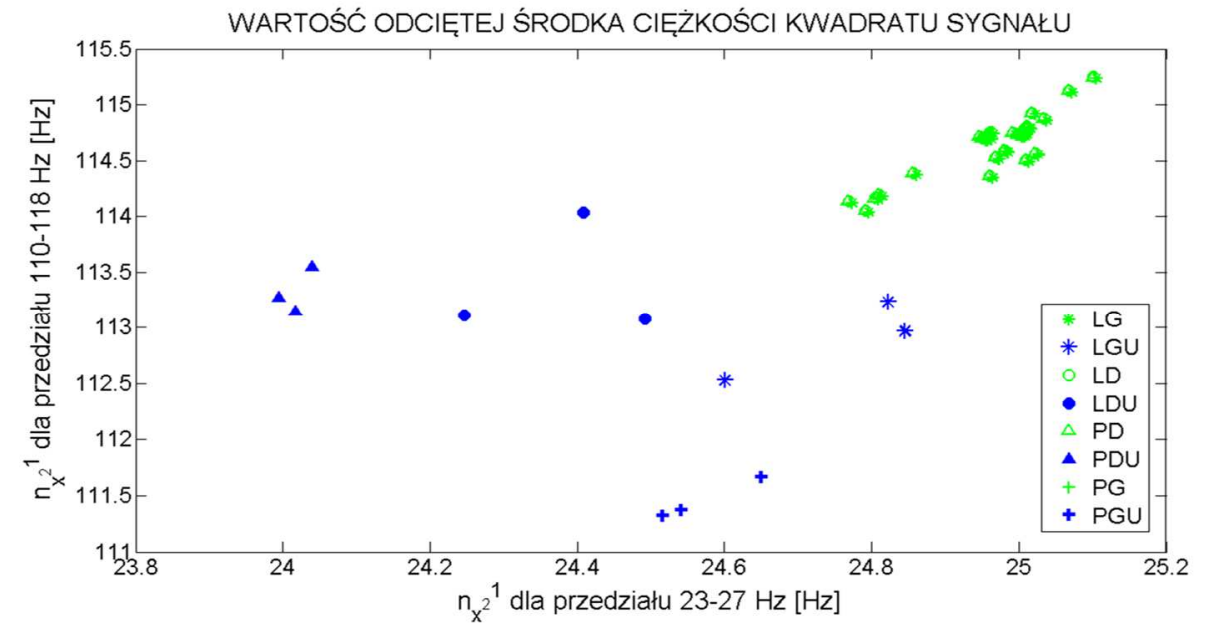

Rys. 9. Porównanie wartości odciętej środka ciężkości kwadratu sygnału w wybranych przedziałach dla wszystkich węzłów (oznaczenia: L - lewy, P- prawy, G- górny, D - dolny węzeł, U - wzorzec uszkodzony, kolor zielony - wzorce bez uszkodzenia)

Fig. 9. Comparison of the center of gravity of the squared signal in selected intervals for all nodes (L - left, P - right, G - top, D - bottom node, U - damaged pattern, green color - patterns without damage) 
Niestety wyłącznie na podstawie informacji o odciętej środka ciężkości całej funkcji nie jest możliwe rozróżnienie wzorców uszkodzonych od nieuszkodzonych. Ma to wyraźny związek z lokalizacją i typem węzła (węzły górne zachowują się nieco inaczej niż dolne). Porównując jednak każdy węzeł osobno można zauważyć, że widoczne na Rys. 7 przesunięcie można wyrazić właśnie poprzez zmianę położenia odciętej środka ciężkości kwadratu sygnału. Opis sygnału przy pomocy wartości $\mathrm{w}$ wytypowanych przedziałach przyniósł znacznie lepsze rezultaty. Na Rys. 9 widoczny jest podział na dwa zbiory - wzorców uszkodzonych i nieuszkodzonych.

Do precyzyjnego rozgraniczenia obu zbiorów użyto metody wektorów nośnych. Ze względu na małą liczbę wzorców zdecydowano się wyłącznie na zastosowanie SVM jako klasyfikatora jednoklasowego. Otrzymany rezultat graficznie przedstawiono na Rys 10 , gdzie czarną linią rozgraniczono obszary odpowiadające uszkodzeniu (na lewo) i prawidłowej pracy konstrukcji (na prawo).

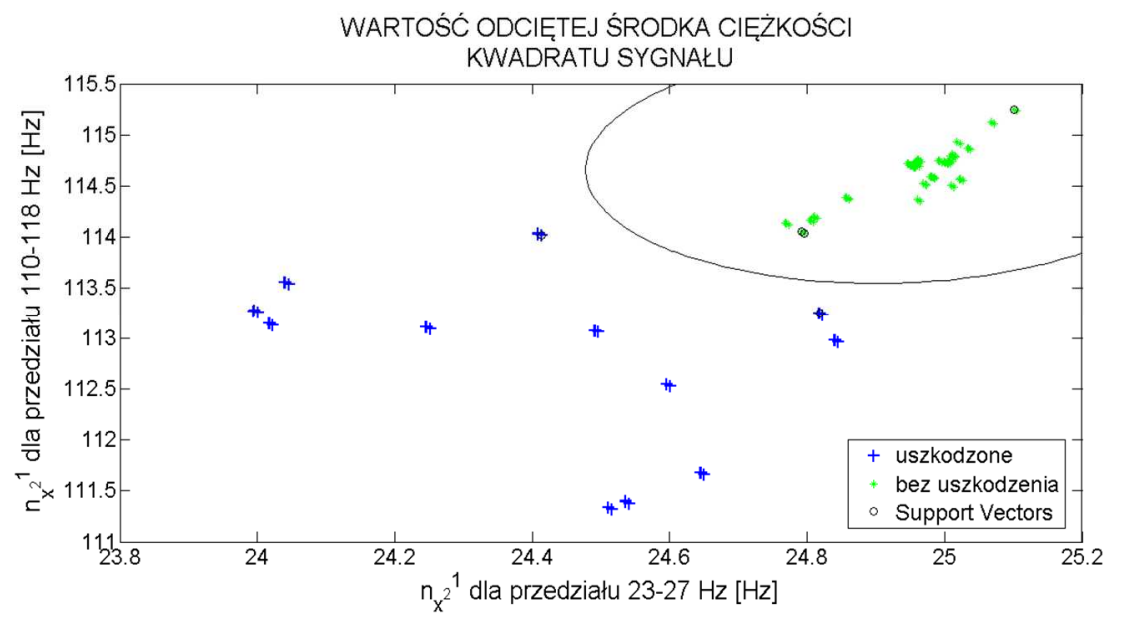

Rys. 10. Podział na wzorce uszkodzone i nieuszkodzone

Fig. 10. Classifying for damaged and undamaged patterns

Analizie poddano również FRF z czujników przy trzech węzłach nieuszkodzonych, rejestrujących drgania w sytuacji, gdy jeden (ostatni) z węzłów ramy uległ uszkodzeniu. Różnice w wartościach analizowanych parametrów są tak małe, że po naniesieniu na płaszczyznę (porównaj Rys. 9 i Rys. 10) widać, że układ jest uszkodzony. 


\section{Wnioski}

Na podstawie przedstawionych wyników można stwierdzić, że wykorzystanie funkcji przejścia do detekcji uszkodzeń ramy stalowej, w połączeniu z metodą wektorów nośnych, daje znacznie większe możliwości od podejścia bazującego wyłącznie na postaciach i częstotliwościach drgań. Przede wszystkim pozwala zredukować liczbę niezbędnych czujników (w przedstawionym przykładzie wystarczy FRF z pomiarów wykonanych jednym czujnikiem przyspieszenia, aby stwierdzić, czy wystąpiło uszkodzenie). Proponowane podejście, na obecnym etapie zaawansowania prac, może być zastosowane do stwierdzenia, że uszkodzenie pojawiło się, przy ograniczeniu wyłącznie do zmian w połączeniach. Ze względu na bardzo małą liczbę wzorców dla każdego typu uszkodzenia nie jest możliwe precyzyjne wskazanie położenia uszkodzenia. Można jednak spodziewać się, że zwiększenie liczby wzorców oraz zastosowanie multiklasowej metody SVM pozwoli na wskazanie uszkodzonego węzła, a uwzględnienie informacji pochodzących z dodatkowych punktów (np. na środku rygli), oraz innych kierunków pomiarowych (np. Z - czyli pionowo w płaszczyźnie ramy) umożliwi wskazanie położenia ewentualnych uszkodzeń na długości poszczególnych elementów, jednak potwierdzenie tego wymaga dalszych badań.

\section{Podziękowania}

Program MATLAB wykorzystany do przeprowadzenia badań zostat zakupiony w wyniku realizacji Projektu nr UDA-RPPK.01.03.00-18-003/10-00 „Budowa, rozbudowa $i$ modernizacja bazy naukowo-badawczej Politechniki Rzeszowskiej” wspótfinansowanego ze środków Unii Europejskiej w ramach Regionalnego Programu Operacyjnego Województwa Podkarpackiego na lata 2007-2013, Priorytet I. Konkurencyjna i Innowacyjna Gospodarka, Działanie 1.3 Regionalny system innowacji.

Do badań wykorzystano aparature zakupiona w projekcie nr POPW.01.03.00-18-012/09 z. Funduszy Strukturalnych w ramach Programu Operacyjnego Rozwój Polski Wschodniej wspólfinansowanego przez. Unię Europejska ze środków Europejskiego Funduszu Rozwoju Regionalnego

\section{Literatura}

[1] Brownjohn J. M. W., De Stefano A., Xu Y.-L., Wenzel H., Aktan A. E.: Vibrationbased monitoring of civil infrastructure: challenges and successes, Journal of Civil Structural Health Monitoring, nr 1, 2011, s. 79-95.

[2] Uhl T., Lisowski W.: Praktyczne problemy analizy modalnej konstrukcji, Wydawnictwo AGO, Kraków 1996.

[3] Arun Kumar K. A., Mallikarjuna Reddy D.: Application of frequency response curvature method for damage detection in beam and plate like structures, IOP Conf. Series: Materials Science and Engineering, 149, 2016, 012160. 
[4] Sulaiman M. S. A., Yunus M. A., Bahari A. R., Abdul Rani M. N.: Identification of damage based on frequency response function (FRF) data, MATEC Web of Conferences 90, 2016, 01025.

[5] Dilena M., Limongelli M.P., Morassi A.: Damage localization in bridges via the FRF interpolation method, Mechanical Systems and Signal Processing 52-53, 2015, s. $162-180$.

[6] Xu Y.L., Huang Q., Zhan S., Su Z.Q., Liu H.J.: FRF-based structural damage detection of controlled buildings with podium structures: Experimental investigation, Journal of Sound and Vibration 333, 2014, s. 2762-2775.

[7] Ziemiański L.: Sieci neuronowe w dynamice konstrukcji. Wybrane zagadnienia, Oficyna Wydawnicza Politechniki Rzeszowskiej, Rzeszów 1999.

[8] Comanducci G., Magalhaes F., Ubertini F., Cunha A.:On vibration-based damage detection by multivariate statistical techniques: Application to a long-span arch bridge, Structural Health Monitoring Vol. 15(5), 2016, s. 505-524.

[9] Dilena M., Limongelli M.P., Morassi A.: Damage localization in bridges via the FRF interpolation method, Mechanical Systems and Signal Processing 52-53, 2015, s. $162-180$.

[10] HosseinAbadi H. Z., Amirfattahi R., Nazari B., Mirdamadi H. R., Atashipour S. A.: GUW-based structural damage detection using WPT statistical features and multiclass SVM, Applied Acoustics 86, 2014, s. 59-70.

[11] Zieliński T. P.: Cyfrowe przetwarznie sygnałów. Od teorii do zastosowań. Wydawnictwa Komunikacji i Łączności, Warszawa, 2005.

\title{
DETECTION OF DEFECTS CONNECTION BETWEEN MEMBERS OF STEEL FRAME ON THE BASIS OF FRF CHANGES
}

\begin{abstract}
S u m m a r y
The article presents the possibility of nodes failures detecting based on the analysis of the proportions between the selected intervals of FRF function. Within the scope of the task an experiment was performed on the laboratory model of a two-storey portal frame, which was subjected to dynamic tests and for which a modal model was defined. FRF function for selected system points was treated as a signal in the frequency domain. For the relevant fragments, the centers of gravity of the signal squares were determined, which were then used as input data in the Support Vector Machines (SVM) method. The proposed approach enables effective detection of connection damage in the tested structure.
\end{abstract}

Keywords: damage detection, SHM, FRF, Support Vector Machines (SVM)

Przestano do redakcji: $10.03 .2017 \mathrm{r}$.

Przyjęto do druku: 28.04.2017 r. 
